\title{
How Precise can be the Residual Stress Determined by X- Ray Diffraction? A summary of the Possibilities and Limits
}

\author{
Eckehard Mueller \\ University of Applied Sciences Bochum, Lennershofstr. 140, D- 44801 Bochum, Germany \\ eckehard.mueller@hs-bochum.de
}

Keywords: Calibration, Residual Stress Measurements, Round Robin Tests

\begin{abstract}
Many springs are shot peened and the quality of shot peening is essential for the fatigue life. Today the determination is often done via x-ray diffraction. The lattice distance is measured and out of this information the residual stress is determined (and not directly measured). For this kind of measurement an absolute measurement is not available. The only way is to calibrate it in some way. It is shown how precise measurements today are in relation to different $\mathrm{x}$-ray diffractometers and a specimen must be designed to get something like a usable calibration sample. The difference between statistical and systematic errors is shown and the consequences of these errors are discussed.
\end{abstract}

\section{Introduction}

Today the determination of residual stresses for many products is a common procedure, e.g. to prove the efficiency of the shot peening process or other hardening processes. Mostly it is done with the help of the x-ray diffraction method, because it is fast and not so expensive. The demands of the automotive industry concerning the accuracy and the number of measurements are still increasing. The question is whether precise measurements can be even performed. Here, round robin tests are reported designed to calibrate such a x-ray-diffractometer.

\section{Basics of stress determination by $x$-rays}

One popular method to determine the residual stresses in springs is the x-ray method. The idea is the measurement of the lattice distance within a solid or spring steel. The basic method is called Bragg reflection. A detailed description of the method will be found in the literature: $[1 ; 2]$. A very brief summary is given here. X-rays with the wavelength $\lambda$ are sent under certain angles $\Psi$ to the surface normal and the diffraction angle $2 \theta$ with the maximum intensity is determined. The following equation can then be used:

$$
\varepsilon=(1+v) / \mathrm{E} * \sigma \sin ^{2} \psi-v / \mathrm{E} *\left(\sigma_{11}+\sigma_{22}\right)
$$

From the measured reflection angle a lattice spacing $D=\lambda /(2 * \sin \theta)$ is determined and is compared with the lattice spacing $\mathrm{D}_{0}$ without any stress $\left(\varepsilon=\left(\mathrm{D}-\mathrm{D}_{0}\right) / \mathrm{D}\right)$. ( $\mathrm{E}$ is the Young's modulus, $v$ is the Poisson's ration, $\sigma_{11}+\sigma_{22}$ are stresses in the main direction on the surface)

The main aspect is that the stress is not measured directly. The lattice parameter is measured at differentangles $\Psi$ and a slope $\mathrm{m}$ is calculated that depends on material constants and the stress thus:

$$
\sigma\left(\mathrm{m}=(1+v) / \mathrm{E}^{*} \sigma\right)
$$

Out of this equation the stress $\sigma$ can be calculated or determined. These considerations show that it is better to speak about determination of residual stress instead of measurement. 


\section{Errors of measurements \\ Introduction}

Every physical measurement has at least two errors: a statistical (or reading) error and a systematical error, which depends on of the equipment. Both errors will be discussed in the following section.

\section{Statistical error}

By measuring with more $\Psi$ angles or by measuring each angle several times the statistical error can be reduced, if there is a linear dependence. Today this kind of error can be reduced in the range of 1 $\%$ with some efforts.

\section{Systematic error}

\section{Surface error}

This x-ray measurement is influenced of the roughness of the surface. For instance, for shot peened surfaces a lower compressive residual stress is usually determined, because there is a relaxation of the residual stresses at the tops of the "surface mountain". It can be more than $25 \%$ less than the compressive residual stress in the surface [3;4]. The consequence is that in the "guideline of measuring residual stresses of shot-peened springs by $x$-ray diffraction" [5] it was suggested that a measurement at $100 \mu \mathrm{m}$ depth or more gives a more reliable value.

\section{Machine error}

The main systematical error is in the machine error. The whole $\mathrm{x}$-ray diffractometer must be aligned. That means the path of the x-rays through the apertures to the detector is in a straight line and must correspond with the detection equipment. Minimal deviations can give results, which show more and less residual stresses. The author has see this several times, because he has access to five diffractometers of the same type. No equipment is available to gauge such a machine like the International Prototype Metre.

The only possibility is to organize round robin tests to optimize the accuracy, which is described in the next section.

\section{Calibration of an $x$-ray-diffractometer \\ Basics}

The long-term stability of an x-ray diffractometer can be monitored using a sample, which has (high) residual stresses. If the sample is stored at normal constant room temperature and no surface corrosion is possible, it can be used many years. This situation is unsatisfactory, because you do not know the systematical deviation of the machine.

\section{Round robin tests}

\section{General demands}

Round robin tests are useful if you have lots of members to get a smaller error of the mean value, which is calculated. The other demand is to have a long-term stability of the sample if it is handled under adequate conditions. The shorter the experiment last the better it is.

\section{General overview of the round robin tests}

In the last 10 years several round robin tests have been made on spring steels. The following table shows the different tests in an overview.

The round robin tests with round material (wire) show dependence between the value of the residual stress and the measuring spot diameter. These experiments are useful in another way, but not for the considerations to get an exact value for calibration. The further the value is away from zero MPa the more meaningful is of the result. The last round robin test fulfils all of the demands, which gives high confidence to the results. There were about 30 participants within a short time. Many measurements at different laboratories in Europe were done on a compressive residual stress sample, which has a high stability. 
Table 1: different round robin tests

\begin{tabular}{|l|l|l|l|l|}
\hline year & sample(s) & organizer & mean value & reference \\
\hline $2006-2009$ & flat & GKN, Mr. Lietzau & $-350 \mathrm{MPa}$ & {$[6[$} \\
\hline $2006-2011$ & flat/round & Rigaku, Mr. Yokohama & $-800 \mathrm{MP}$ & {$[7]$} \\
\hline 2013 & round & VDFI, Prof. Mueller & $-650 \mathrm{MPa}$ & {$[8]$} \\
\hline $2012-2014$ & flat & GKN, Mr. Lietzau & $+550 /-1120 \mathrm{MPa}$ & {$[9[$} \\
\hline
\end{tabular}

Demands on the sample

The sample should not have curvatures at the surface and the roughness should be as low as possible (see section below). On the other hand, the sample should have a high residual stress to be far away from the zero point. The consequence is that the tensile strength of the material must be high. If one takes all aspects into consideration spring steel, which is deep rolled, fulfills the demands. It is also easy to produce.

Materials for normal leaf springs were taken and after hardening the material was quenched to get a tensile strength $\mathrm{R}_{\mathrm{m}}=1500 \mathrm{MPa}$. The surface was ground to remove the decarburization, which is always on the surface. To be sure, at least $1 \mathrm{~mm}$ was removed. Afterwards an area of $55 \mathrm{~mm}$ * $55 \mathrm{~mm}$ was deep rolled in a meandering pattern like shown in fig. 1. Deep rolling at this high tensile strength gives low roughness combined with high compressive residual stresses at the surface.

\section{Practical realization}

A practical realization is shown in fig. 2. Two samples were deep rolled with an HG6-tool (from Ecoroll). The track distance $\Delta \mathrm{x}$ was optimized to $\Delta \mathrm{x}=0.15 \mathrm{~mm}$ [10]. The diameter of the ball was $6 \mathrm{~mm}$ and the pressure was 100 bar. The roughness $R_{z}$ is between 5 and $12 \mu \mathrm{m}$. Perpendicular to the rolling track you produce compressive residual stresses $\sigma$ of nearly $\sigma=2 / 3 *$ $\mathrm{R}_{\mathrm{m}}$, which means around $900 \mathrm{MPa}$.

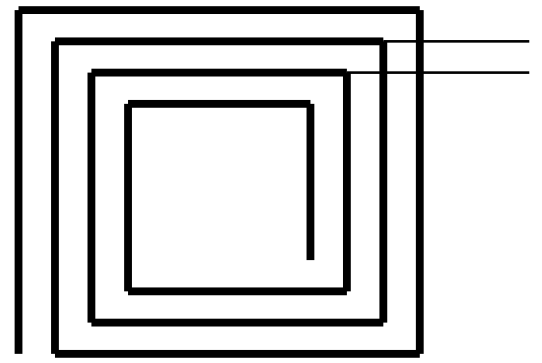

Fig. 1: tracking of the sample

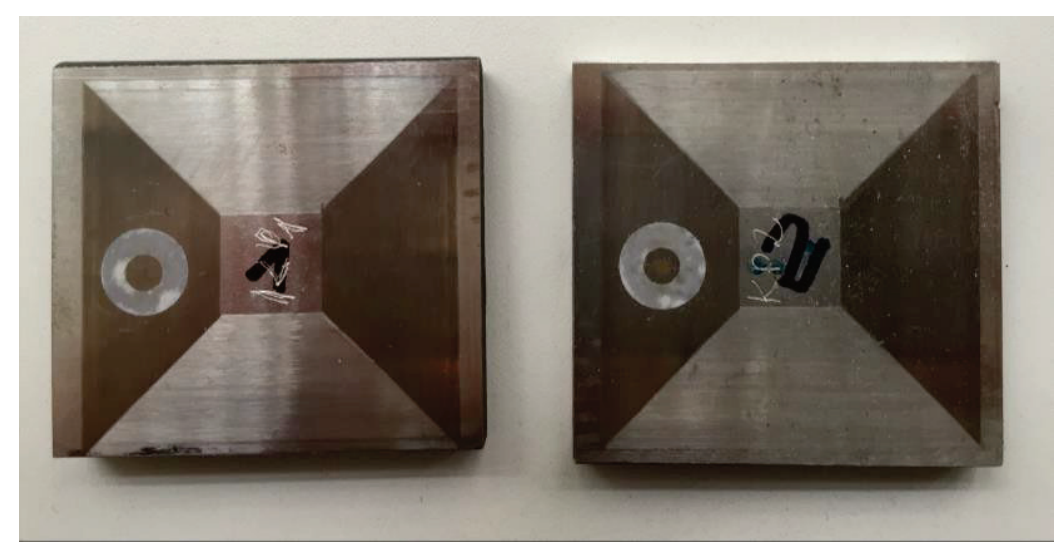

Fig. 2: realization of the samples

Mr. Lietzau of the company GKN (Germany) organized several times a great round robin test in Europe. He uses a sample of the same structure, which was also made by the author. About 30 different laboratories measured the sample within less than two years. The result is that a sample 
is available with a known compressive residual stress $\sigma=-1120 \mathrm{MPa}+/-43 \mathrm{MPa}$ [9]. A deviation of more than $100 \mathrm{MPa}$ from the average was seen at some labs.

The samples shown in fig. 2 were produced from this "mother sample". They have a residual stress of about $\sigma=-925 \mathrm{MPa}$ with nearly the same absolute error. These samples can be used to calibrate $\mathrm{x}$ - ray measuring equipment [11].

\section{Conclusions}

When comparing residual stresses from different labs, one must keep in mind that there may be great differences measuring the same objects (e.g. springs). To minimize the variation a calibration sample that has been used in round robin tests is useful. Laboratories have to make their own samples to monitor the long- term stability. Today an absolute calibration of an x-ray diffractometer is not possible and the measurements have a systematic uncertainty of at least 5 $\%$.

In many (delivery) specifications very small errors are claimed, which are in no relation to the systematic uncertainty of $50 \mathrm{MPa}$ respectively $5 \%$. One way to solve the problem is to organize round robin tests with a huge number of participants.

\section{Acknowledgements}

I thank Mr. Lietzau of GKN for his great efforts to organize and evaluate this big round robin test. $\mathrm{He}$ is permanently working to improve the uncertainties of the calibration $\mathrm{x}$-ray measuring equipment.

\section{References}

[1] Noyan I. C. u. J. B. Cohen: Residual Stress, Springer Verlag, New York, 1987. http://dx.doi.org/10.1007/978-1-4613-9570-6

[2] SAE-Paper: Residual Stress Measurements by X-Ray Diffraction, No.: SAE J784a, Warrendale, 1971.

[3] Müller, E.: Messung von Lastspannungen bei verschiedenen Oberflächenrauhigkeiten mit Hilfe eines Röntgendiffraktometers, HTM 48 (1993) 1/93, pp. 50 - 52.

[4] Müller, E.: The Difficulty of Measuring the Residual Stress at Shot Peened Surfaces, MFN (Metal Finishing News), Vol.11, Nov. 2010, pp. $60-61$.

[5] VDFI (German Spring Association): Guideline 8501: Messung von Eigenspannungen durch Röntgenografie an kugelgestrahlten Federn, Verband der deutschen Federnindustrie, Hagen (Germany), Febr. 2012.

[6] Lietzau, J. Ringversuch Eigenspannungen, talk given at the Sitzung des AWT FA13 „Eigenspannungen“, Freiburg, (Germany) 29.04.2008

[7] Yokohama, R.: X-ray Residual Stress Evaluation of Springs, Rigaku Cooperation, talk given in Donnguan (China), June 2013.

[8] Müller, E.: Ringversuch - Eigenspannungen, Verband der deutschen Federnindustrie, talk given at the Jahreshauptversammlung, Leipzig (Germany), May 2014.

[9] Lietzau, J.: Materials Engineering Report No. 18_L13167, released 22 Oct. 2014, GKN Driveline Int. GmbH, Lohmar, 2014.

[10] Müller, E.: Evolution of the residual stresses by stress rolling, in V. Schulze u. A. Nikul-Lari (Editor): Shot Peening and other Mechanical Surface Treatments, IITTInternational, Noisy-le-Grand, 2005, pp. 436- 441.

[11] Müller, E.: Die Messung von Eigenspannungen mittels Röntgendiffraktion und die Sinnhaftigkeit der Fehlernangabe, in Borsutzki, B und Moninger, G (Editor): Fortschritte in der Werkstoffprüfung für Forschung und Praxis, Verlag Stahleisen, Düsseldorf, 2015, pp. 215 - 219. 